\title{
EQUIDADE ENTRE A JUSTIÇA E A POLITICA: A VERTENTE CASUALISTA
}

\section{Roosevelt Arraes ${ }^{1}$}

\section{Resumo}

O artigo versa sobre a equidade, a qual é entendida como recurso do intérprete contra a lei e o precedente. A partir da investigação de textos doutrinários, de decisões judiciais e de normas do direito brasileiro, a equidade é apresentada sob duas perspectivas, a casualista e a abstracionista. Analisa-se a vertente casualista, indicando e exemplificando as hipóteses em que as Cortes do país aplicam-na. Alguns precedentes do STF demonstram que a equidade pode ser mais iníqua que as decisões tradicionais. No entanto, argumentos conduzidos de maneira imparcial, justificáveis publicamente, podem melhorar a qualidade do julgamento por equidade, tornando-o mais razoável para a solução de casos difíceis.

Palavras-chave: equidade, justiça, vertente casualista, justificação, razoabilidade.

\section{INTRODUÇÃO}

A tomada de decisões por equidade é tão antiga quanto o surgimento do direito. O rei Salomão viu-se numa situação difícil ao ter que decidir sobre a maternidade de uma criança, tendo que ser criativo para encontrar a melhor solução para o caso concreto. Os pretores peregrinos, na Roma antiga, a utilizavam para construir soluções em conflitos que envolviam cidadãos romanos e estrangeiros. ${ }^{2} \mathrm{Na}$ ausência de regras inovavam com fórmulas que se tornavam paradigmas para a decisão de outros casos.

Modernamente, com a crescente influência do positivismo lógico-jurídico, a equidade perdeu seu prestígio e praticamente caiu em desuso, em razão dos pressupostos da infalibilidade do legislador e da capacidade cognitiva do intérprete de desvendar enunciados normativos. Estes pressupostos, aliás, caracterizam os Estados de Direito ocidentais do sec. XX, especialmente os vinculados à tradição civil law.

No entanto, o funcionalismo jurídico positivista passou a evidenciar suas limitações a partir de meados do século passado, em razão da incorporação de valores, princípios e cláusulas gerais nas declarações internacionais de direitos e nas Constituições.

\footnotetext{
${ }^{1}$ Doutorando (2016) em Filosofia Jurídica e Política pela Pontifícia Universidade Católica do Paraná. Professor e pesquisador do Centro Universitário Curitiba - UNICURITIBA e membro-pesquisador do Departamento de Filosofia na Pontifícia Universidade Católica do Paraná. E-mail: arraes@aac.adv.br
} _vol.09, nº. 04, Rio de Janeiro, 2016.pp. 1935-1954 
É neste espaço que a equidade se reinsere, ainda que de forma tímida (às vezes, implicitamente), pois, há certa relutância na sua aceitação.

Este artigo objetiva apresentar uma das vertentes (a casualista) que trata do tema, procurando mostrar que o emprego da equidade é necessário e que os riscos para a segurança jurídica podem ser equacionados em parte. Não se ignora que da equidade pode resultar decisões arbitrárias (do campo do Político) ${ }^{3}$, mas, a opção contrária (a insistência na aplicação de uma regra ou precedente pré-existentes) pode ser igualmente polêmica e inadequada para o caso concreto.

O texto está dividido nos seguintes tópicos: a) apresentação inicial das acepções da equidade, na qual se fará a distinção entre a vertente casualista (que prioriza a construção das soluções a partir do contexto do caso concreto) e a vertente abstracionista (que prioriza a construção da solução a partir de uma teoria geral sobre a justiça; b) caracterização dos pontos comuns de ambas as vertentes; c) a indicação das hipóteses de cabimento e a exemplificação de casos em que as Cortes brasileiras aplicaram a equidade; d) ponderações sobre a forma de produzir argumentos equitativos justificáveis publicamente.

A metodologia empregada para a confecção do artigo pautou-se na investigação de textos doutrinários, de precedentes e de normas do direito brasileiro. Tais elementos serviram de suporte para as considerações formuladas sobre o tema investigado.

\section{ACEPÇÕES DA EQUIDADE}

A equidade está na última fronteira do direito. Nela encontram-se os elementos jurídicos, concernentes à imparcialidade, à regularidade e à consistência argumentativa. Ou seja, quanto à forma, a equidade ostenta atributos próprios das normas jurídicas. Mas, nela também estão presentes elementos extrajurídicos, os quais, ante a pretensão de se fazer valer a justiça, a razoabilidade ou o bom-senso, muitas vezes ocultam o caráter arbitrário de uma decisão que desvia da lei ou do precedente.

Nos confins do direito, lá onde o campo do Político se arvora é que se encontra a equidade, um campo duplo de juízos e argumentos que flerta com o decisionismo ${ }^{4}$. Nesse sentido, o conteúdo do juízo de equidade não é previamente definível ou delimitável.

\footnotetext{
${ }^{2} \mathrm{O}$ direito romano tinha regras para as relações jurídicas estabelecidas entre cidadãos (ius civile) e regras para os estrangeiros (ius gentium). Quando se travavam relações entre cidadãos e estrangeiros, cabia ao pretor peregrino construir soluções criativas para o conflito.

${ }^{3}$ Toda decisão equitativa é, em alguma medida política, no sentido de ser discricionária. Aliás, é discricionária num sentido especial, pois, equivale à discricionariedade do legislador. Como afirma Perelman, o magistrado é o legislador do caso concreto. Mas, uma decisão discricionária (política), que implica numa escolha valorativa não precisa ser arbitrária, violando a ordem jurídica existente de maneira a torná-la insuportável como os comandos de um ditador num estado de exceção (campo do Político).

${ }^{4}$ Nesse sentido, afirma Carl Schmitt: "Cada decisión jurídica concreta contiene un elemento de indiferencia con respecto al contenido porque la conclusión jurídica no emana en su totalidade de sus premisas y el hecho de ser necesaria la decisión se conserva como elemento determinante autónomo." (SCHMITT, 2004, p. 90).
} 
Noutros termos, ante sua peculiaridade, não é possível defini-la por oposição, contraste ou negação. E quando ela se define internamente, não há nenhum critério (teórico, objetivo, jurídico ou político) a validá-la de maneira absolutamente neutra.

Apesar dessas dificuldades, é possível traçar um panorama da equidade a partir do modelo teórico ou do procedimento argumentativo que se emprega na solução de casos difíceis, o que permite, senão uma resposta definitiva sobre o problema do decisionismo, ao menos aponta alguns limites à atuação dos juristas, dos administradores públicos e dos cidadãos envolvidos na discussão das regras jurídicas.

São duas perspectivas que aparentemente se contradizem, mas, por fim se complementam. Elas não são totalmente independentes, mas, ao menos num plano mais abstrato, é possível distingui-las.

Seria possível sugerir outras acepções para a equidade, mas as apresentadas a seguir parecem organizar de maneira adequada duas grandes linhas do pensamento político, filosófico e jurídico que tratam do tema.

Uma linha toma a equidade a partir de casos concretos, e, a partir deles procura ter uma visão mais ampla da justiça. Esta linha, que remonta a Aristóteles e aos juristas do direito romano antigo, chega à modernidade, por exemplo, pelo pensamento de Chaïm Perelman. Essa vertente é mais atenta às peculiaridades do caso concreto, porém, enfrenta sérias dificuldades de aplicação num plano mais amplo, sendo, por isso mesmo, acusada de falta de objetividade e imparcialidade, o que revelaria seu caráter arbitrário e excessivamente Político. Esta é a vertente de "casualista".

A outra vertente toma a equidade como um modelo mais geral e abstrato, que orienta as instituições mais relevantes da sociedade, para, então, verificar sua aplicabilidade em casos concretos. Nessa linha, têm-se as construções teóricas de contratualistas liberais modernos, como John Rawls, que intitula sua teoria de "justiça como equidade". Ao passo que esta vertente oferece um panorama institucional orientado para um fim específico, que no entender destes autores seria menos arbitrário, ela tem dificuldades na solução de casos particulares mais complexos. Eis a vertente de "abstracionista".

Tais vertentes dividem a atenção de juristas, políticos e filósofos de maneira inconciliável, e, a questão parece não estar perto de ser resolvida. Todavia, conforme se argumentará a seguir, ao definir o âmbito da aplicação de cada qual, é possível, senão resolver o problema a partir dos fundamentos, ao menos justificar porque podem oferecer respostas menos arbitrárias aos problemas jurídicos-políticos das sociedades democráticas modernas

\section{PONTO COMUNS ENTRE A VERTENTE CASUALISTA E A ABSTRACIONISTA}

Tanto a vertente casualista quanto a vertente abstracionista entendem que a equidade não é a legalidade positivada num ordenamento jurídico. A equidade é uma forma de justiça melhor que a justiça legal. Como afirma 
Aristóteles, a equidade não é o justo segundo a lei, e sim um corretivo da lei, isto porque "toda lei é de ordem geral, mas não é possível fazer uma afirmação universal que seja correta em relação a certos casos particulares.” (ARISTÓTELES, 2001, p. 109).

Nesse ponto faz-se necessária uma observação, porque, a legalidade também pode ser entendida como um conjunto de comandos normativos não positivados, ou, mesmo que positivados, fundada em princípios racionais de caráter moral, que estabeleceriam um parâmetro para completude do direito posto (legalidade).

Exemplo dessa perspectiva encontra-se em Kant para quem a equidade não passa de um engano, isto porque, para um sistema jurídico racional, derivado de imperativos morais formais (a priori), que formatam o direito, não é possível outra opção de juízos de valor. O pensamento kantiano trabalha com os binômios moralidade-imoralidade, legalidade-ilegalidade, lícito-ilícito, e, nestas dualidades não há espaço para uma terceira categoria (do razoável ${ }^{5}$, do equitativo). Daí a afirmação de que a equidade não passa de um erro, pois não se amolda a quaisquer destas categorias, não passando de mera opinião subjetiva do magistrado.

"A equidade (considerada objetivamente) não é, de modo algum, uma base para meramente intimar outrem a cumprir um dever ético (ser benevolente e bondoso). Alguém que exige alguma coisa apoiado nessa base, ao contrário, se funda em seu direito, porém, não possui as condições necessárias a um juiz para determinar em quanto ou de que maneira sua reivindicação poderia ser satisfeita.

(...)

A divisa (dictum) da equidade é: 'o direito mais estrito é a maior injustiça (summun ius summa iniuria)'. Mas este mal não pode ser remediado por meio do que é estabelecido como direito, embora diga respeito a uma reivindicação a um direito, pois esta reivindicação pertence apenas ao tribunal da consciência (forum poli), ao passo que toda questão do que é estabelecido como direito tem que ser apresentada ante o direito civil (forum soli)." (KANT, 2003, p. 80-1)

Apesar da oposição kantiana, no sentido de que casos particulares não devem ser tratados de maneira diferente, não se pode negar a força e a aplicabilidade da equidade, notadamente num ambiente epistemológico pós-moderno que critica os conteúdos jurídicos fundados "na teologia da história, na constituição do homem ou no fundo casual de tradições bem-sucedidas" (HABERMAS, 2003, p. 19), porque não produzem valores unânimes.

O objetivo não é de aprofundar este tema (relacionado à pretensão de superação da filosofia do sujeito), bastando retomar a discussão de Kant sobre o direito de família ${ }^{6}$, sobre a função da culpa e o direito de punir, para

\footnotetext{
${ }^{5}$ É possível extrair da obra de Kant a ideia do "razoável". É o que afirma Rawls quando aponta que o imperativo categórico é uma forma de se racionar de tal maneira que o agente compatibilize os seus fins com os fins das demais pessoas. No entanto, o "razoável" kantiano está apenas no plano teórico. Uma vez estipulado um dever (presumidamente razoável) não há espaço para outra interpretação do que se deva (ou não) fazer. Diferentemente, a equidade aplica o "razoável" num caso específico.

${ }^{6}$ Segundo Kant: "A união sexual natural ocorre ou de acordo com a mera natureza anima (vaga libido, vênus valgivaga, fornicatio) ou de acordo com a lei. A união sexual de acordo com a lei é o casamento (matrimonium), isto é, a união de duas pessoas de sexos diferentes para a posse por toda a vida dos atributos sexuais recíprocos." (KANT, 2003, p. 122). Tal visão do casamento, defendida por alguns grupos religiosos na atualidade está longe de ser a única forma de união protegida pelo Estado. Daí a polêmica sobre os conceitos jurídicos extraídos da filosofia moral kantiana.
} 
perceber que o resultado de sua construção teórica (fundada a partir da perspectiva do sujeito racional) não é incontroverso nas sociedades contemporâneas, que aceitam o pluralismo moral, religioso e filosófico. Noutros termos, a visão unitária da moralidade (e do direito) das filosofias do sujeito (a exemplo da kantiana) não são suficientes para oferecer a pretendida completude ao direito. Por conseguinte, torna-se inevitável a discussão sobre a aplicação da equidade.

Pois bem, como afirmado anteriormente, há uma ideia geral, ao menos entre aqueles que a defendem, de que a equidade é melhor que o justo legal. Obviamente, aqueles que defendem a aplicação da equidade num sistema jurídico não estão se referindo a um modelo perfeito de regras, como pretendia Kant.

Ao contrário, os que admitem a aplicação da equidade reconhecem que mesmo num ordenamento jurídico, com regras claras, objetivas e vinculantes podem surgir arbitrariedades e resultados iníquos em certas circunstâncias.

Tanto casualistas, quanto abstracionistas pressupõem um ordenamento jurídico incompleto, falho, sujeito a revisões (não só pelo legislador, mas por todos os atores das instituições públicas, especialmente os do Judiciário), que jamais alcançará seu objetivo último, qual seja, tornar-se um sistema de regras que, apesar de complexo, produz respostas verdadeiras sobre o que élícito/ilícito.

Como afirma Francisco Cardozo de Oliveira: "A origem da insuficiência, portanto, não está no conceito. (...) Os limites do conceito resultam em última análise dos obstáculos que impedem a emergência da verdade e da justiça, na realidade social e histórica do presente." (OLIVEIRA, 2006, p. 269).7

Esse pressuposto cauteloso sobre a força explicativa de um ordenamento jurídico não autoriza dizer que os defensores da equidade negam valores como o da segurança jurídica, o respeito aos precedentes, à legalidade e à separação de poderes. $\mathrm{Na}$ verdade, para eles, tais valores não são absolutos e podem ceder espaços a considerações de justiça, que implicam num desvio à interpretação tradicional da regra positivada, e, por evidente, num redimensionamento de forças entre aqueles que se encarregam da criação e da aplicação do direito.

A pretensão de completude do ordenamento jurídico também é compartilhada pelos que recorrem ao uso da equidade. Mas, estes reconhecem que o ordenamento jurídico é passível de inconsistências, não restando alternativa senão socorrer-se de mecanismos racionais para adequá-lo e conformá-lo ante as prováveis (inevitáveis) perplexidades decorrentes de complexas operações jurídicas.

Noutros termos, para ambas as vertentes (casualistas e abstracionistas) o fato de um ordenamento jurídico prever (ou não) a aplicação da "equidade", como se pode extrair dos arts. $4^{\circ}$ e $5^{\circ}$ do Decreto-Lei n. ${ }^{\circ}$ 4.657/42 (Lei de Introdução às Normas do Direito Brasileiro), é indiferente, porque independentemente de

\footnotetext{
${ }^{7}$ No mesmo sentido, tem-se o seguinte comentário do Min. Eros Grau, do STF, na ADI n.o 2240/BA: "A ADI que temos sob julgamento compreende não apenas o pedido de declaração de inconstitucionalidade de uma lei, mas também vol.09, no. 04, Rio de Janeiro, 2016. pp. 1935-1954 
previsão expressa (seja ela de caráter constitucional ou infraconstitucional ${ }^{8}$ ) o resultado é o mesmo, ou seja, a "equidade" é inerente ao ordenamento jurídico e tem aplicação, ainda que de maneira implícita."

De toda forma, o uso da equidade é reconhecido no direito tributário (art. 40 do Decreto n. ${ }^{\circ}$ 70.235/72), no direito administrativo, conforme se extrai do art. 2º, II, VI e XIII da Lei n. 9.784/99, no direito do trabalho, em razão da notória atuação criativa dos magistrados, especialmente em dissídios coletivos, conforme autoriza o art. 114, \$2 da Constituição e no novo Código de Processo Civil (Lei n. 13.105/2015), que no art. 140, parágrafo único, traz a possibilidade de aplicação da equidade quando houver autorização legal. ${ }^{10}$

Esse desvio às regras positivadas, e a consequente necessidade de construção de decisões equitativas, é cada vez mais frequente (e polêmica) no Poder Judiciário, o qual, invocando princípios e cláusulas gerais da Constituição, por vezes parece substituir o legislador ou o administrador público eleito democraticamente.

Sem ingressar nesta polêmica, importam destacar os pontos de convergência entre as vertentes indicadas, quais sejam: a) pressuposição da insuficiência do ordenamento jurídico; b) a possibilidade de aplicação da equidade, independentemente de previsão legislativa; c) a mitigação da força dos institutos clássicos do direito.

A seguir será analisada a vertente casualista.

\section{A VERTENTE CASUALISTA}

A vertente casualista, como sobredito, enfoca os casos concretos, e, partir de circunstâncias especiais identifica os limites do ordenamento jurídico, ou seja, o caso em que a legislação e os precedentes conhecidos não são capazes de oferecer uma resposta satisfatória.

Não é que os casualistas desprezem a segurança jurídica. Na verdade, eles a prezam, porém, sem hiperdimensioná-la. Ou seja, enquanto as regras e precedentes oferecem respostas razoáveis, eles continuarão a ser utilizados. No entanto, quando eles se encontrarem em situações limites, afasta-se a segurança jurídica para se construir uma nova solução para o caso concreto, que também deverá, doravante, ser aplicada com segurança

inconstitucionalidade, institucional, de um ente da federação. Este caso não pode ser examinado no plano do abstracionismo normativista, como se devêssemos prestar contas a Kelsen e não a uma ordem concreta." (p. 15)

${ }^{8}$ Nesse sentido: "A equidade, que se identifica com a razoabilidade, com a proporcionalidade e com a vedação do excesso, pode e deve estar presente em toda decisão judicial, independentemente de haver autorização expressa em Lei." (VARGAS, 2015, p. 89)

${ }^{9}$ Obviamente, que a posição daqueles que acreditam na completude e perfeição do sistema jurídico, afirmando que suas dificuldades não autorizam o emprego da equidade, insistirão que na ausência de positivação da "equidade" não poderá o magistrado dela se valer. Tal polêmica não é passível de solução porque está assentada em crenças racionais de caráter pessoal, em categorias e conceitos que procuram mostrar o erro das correntes opositoras. Como ato de crença (ou como "pressuposto", para utilizar um termo mais vinculado à pretensão de verdade), assume-se, para fins argumentativos, que a incompletude do direito é um fato, e, por conseguinte, a equidade, uma forma de superá-la, de maneira menos arbitrária.

${ }^{10}$ A previsão incorre em petição de princípio, porque supõe que a legalidade (incompleta) pode descrever (de maneira completa) o caso em que a equidade poderá ser utilizada. No entanto, é o contrário que se dá. Ou seja, é justamente em razão da incompletude da lei, que se invoca a equidade. E, por isso mesmo, não pode a lei, na sua incompletude, pretender delimitar as hipóteses de aplicação da equidade. Seria o mesmo que dar por resolvido o paradoxo de Zenão, de supor que o finito (a previsão legal) pudesse apreender o infinito (os casos concretos nos quais se faz necessária a equidade). 
jurídica.

A equidade é um recurso do juiz (do administrador público e dos demais intérpretes) contra lei, que se aplica nas seguintes hipóteses:

"apela-se ao seu senso de equidade quando a lei, aplicada rigorosamente, em conformidade com a regra de justiça, ou quando o precedente, seguido à letra, conduzem a consequências iníquas. Isso pode ser explicado por três razões: a primeira, aquela a que Aristóteles alude, é a obrigação de aplicar a lei a um caso singular, no qual o legislador não pensara; a segunda se apresenta quando condições externas, tais como uma desvalorização da moeda, uma guerra ou catástrofe, modificam tanto as condições do contrato que sua execução estrita lesa gravemente uma das partes; a terceira se deve à evolução do sentimento moral, do que resulta que certas distinções, que o legislador, ou o juiz que havia enunciado o precedente, havia menosprezado no passado, se tornam essenciais na apreciação atual dos fatos." (PERELMAN, 1996, p. 163)

Alguns exemplos podem ilustrar a maneira como se invoca a equidade para resolver casos difíceis, ou seja, aqueles em que as respostas necessitam ser construídas pelo julgador (magistrado ou administrador público).

Uma hipótese de peculiaridade do caso concreto, que autoriza um desvio à regra de justiça ou ao precedente, pode ser identificada na decisão proferida na Apelação/Reexame Necessário n. 612631 do TRF da $2^{\text {a }}$ Região ${ }^{11}$, na qual se discutiu a possibilidade de somente candidatas do sexo feminino participarem de concurso público para o cargo de psicóloga para o atendimento a mulheres vítimas de violência.

A considerar as disposições do art. 5, I e II c/c 37, I, II e XXI da Constituição a resposta a ser dada ao caso concreto era de que, inexistindo regra específica, deveria prevalecer a isonomia entre homens e mulheres, de maneira que também os homens poderiam participar do concurso público. No entanto, invocando a razoabilidade $^{12}$, o Tribunal Regional Federal da 2a Região entendeu que, diante da peculiaridade do caso concerto (concurso público para atendimento de mulheres vítimas de atos violentos), impunha-se desviar da regra de justiça (isonomia) para aceitar a diferença excepcional entre os gêneros. ${ }^{13}$

\footnotetext{
${ }^{11}$ TRF2, Apelação/Reexame Necessário 612631, Rel. Des. Carmen Silvia Lima de Arruda, 6a Turma, E-DJF2R 07.04.2014.

${ }^{12}$ O precedente analisado refere-se ao: “(..) critério bastante razoável dada as peculiaridades do cargo destinado a complementar estrutura do Centro de Referência de Atendimento à Mulher em Situação de Violência, órgão integrante da referida Coordenadoria, nos termos do referido diploma legal, sendo forçoso reconhecer, nesta hipótese, tratamento diferenciado, sem que isso implique ofensa ao princípio da isonomia. 6. Em que pese a Lei não ser explícita no que tange às especificidades do cargo de psicólogo mormente em relação ao atendimento a mulheres vítimas de violência, da análise sistemática de seu texto, é possível depreender que o objetivo do legislador foi criar uma estrutura organizacional administrativa ligada à Prefeitura para prestação de atendimento e auxílio a mulheres em situação de risco, especialmente quanto a questões jurídicas, psicológicas e sociais.". Há uma severa discussão sobre qualificar-se a razoabilidade como equidade, ou, como proporcionalidade (em sentido estrito, como adequação e como necessidade da providência concreta). Alguns, aliás negam que os conceitos sejam uma mesma coisa. Os julgados analisados valem-se da equidade ora sob o signo "razoabilidade", ora valendo-se do termo "proporcionalidade", não havendo uma conclusão definitiva sobre a nomenclatura.

${ }^{13}$ Embora para alguns pareça desnecessária a discussão acerca da possibilidade (e dos limites) de aplicação da equidade, não se pode ignorar que a sua rejeição pode justificar soluções jurídicas no mínimo polêmicas. É o que se verifica nos precedentes abaixo colacionados, que aplicaram regras arbitrárias (sem qualquer consideração de equidade) para impedir que mulheres (no século $\mathrm{XX}$ ) participassem de concurso público. Ou seja, as mulheres não reivindicavam uma vaga especial, ou um tratamento diferenciado (mais vantajoso) no concurso. Elas queriam, simplesmente, participar do concurso. No entanto, embora pudessem votar e participar da vida pública (ainda que de maneira não tão intensa), tal direito lhes foi negado em razão da aplicação da lei (dura lex, sed lex). Nesse sentido, tem-se os seguintes precedentes: STF, RE 89534/PR, Rel. Min. Décio Miranda, 2a Turma, j. j. 29.04.1980,
} vol.09, nº. 04, Rio de Janeiro, 2016.pp. 1935-1954 1941 
Uma hipótese de catástrofe, ou, momento de abrupta crise que pode ensejar a modificação da regra de justiça, é encontrada no julgamento do Recurso Especial n. ${ }^{0} 437660^{14}$, que enfrentou a discussão sobre a possibilidade de revisão de cláusula de contrato de leasing que previa a variação cambial para fins de correção das prestações.

No mesmo sentido, têm-se os seguintes precedentes do STJ, todos envolvendo a necessidade de se reconstruir as regras contratuais: AGA 449.457, AGA 446.464 e REsp 343.617. Em alguns destes precedentes há a invocação do Código de Defesa do Consumidor, o que poderia levar a crer que a Corte não teria aplicado a equidade.

Todavia, o que há de destaque nos referidos precedentes é que, diante da grave crise financeira pela qual passou o país em 1999, os contratos indexados pelo dólar (esta era a regra de justiça que, aliás, até aquele momento, era favorável ao consumidor) deveriam ter suas regras alteradas.

Ou seja, a Corte reconheceu "A súbita alteração na política cambial, condensada na maxidesvalorização do real, ocorrida em janeiro de 1999" que "criou a circunstância da onerosidade excessiva, a justificar a revisão judicial da cláusula que a instituiu”.

Daí decorreu a atuação da Corte, a qual substituiu a vontade das partes. Perceba-se que se não houvesse a crise, e, algum consumidor inadimplisse suas obrigações, é provável que inexistisse discussão sobre o seu dever de honrar o contrato na forma pactuada, a qual, repita-se, lhe era favorável.

Mas, diante do evento excepcional, a Corte foi obrigada a ponderar que não seria justo exigir que uma parte arcasse com encargos excessivos que a empobreceriam significativamente, isto sem que o credor the oferecesse alguma contrapartida.

Por outro lado, o Superior Tribunal de Justiça poderia simplesmente ter convertido o valor do contrato em moeda nacional e determinar que o consumidor pagasse este valor sem qualquer correção monetária ou remuneração pelo capital emprestado (já que os contratos não traziam esta sistemática).

O STJ, porém, ponderou que não seria razoável impor as perdas inflacionárias às instituições financeiras, que possibilitaram a satisfação da necessidade do consumidor por meio do fornecimento do crédito. E tal crédito, além de atualizado monetariamente, deveria ser remunerado (juros), isto para que houvesse: "a distribuição, entre

DJ 16.05.1980, p. 3486, Ement. VOl. 01171-02, p. 405; (STF RMS 8783/SP, Re. Min. Antonio Villas Boas, Tribunal Pleno, j. 30.08.1961, DJ 06.10.1961, Ement. vol. 479-01, p. 262). Por outro lado, na linha dos precedentes anteriormente apresentados, também encontram-se decisões interessante sobre o tipo de profissão que poderia ser exercido somente por um dos gêneros, isto em razão de aplicação literal da lei: "Parteira prática. Só pessoa do sexo feminino pode exercer essa profissão, pode inscrever-se em provas públicas de habilitação para obter o certificado, o diploma de referência. Constitucionalidade dos arts. 10, 7o, 12 e 13 do decreto-lei no 8.778, de 1946." (STF, RMS 9963/PR, Rel. Min. Gonçalves de Oliveira, j. 28.11.1962, Tribunal Pleno, DJ 17.12.1963, p. 4448, Ement. Vol. 566-02, p. 702). O que importa perceber nestas reflexões é que a lei, tanto num caso, quanto noutro, é aplicada sem considerações de equidade.

${ }^{14}$ STJ, REsp 437660, Rel. Min. Sálvio de Figueiredo Teixeira, 4a Turma, DJ 05.05.2003, p. 306, RDDP vol. 6, p. 111, RST vol. 168, p 412. 
arrendantes e arrendatários, dos ônus da modificação súbita da política cambial com a significativa valorização do dólar americano."

Assim, repita-se, diante da situação excepcional, a Corte foi obrigada a construir uma solução (meio termo) a fim de que nenhuma parte enriquecesse indevidamente, em detrimento da outra, ou que sofresse perdas excessivas sem que nada lhe fosse proporcionado como contrapartida.

Como sobredito, trata-se de uma situação extraordinária na qual a legislação, por si só, não poderia fornecer uma única resposta verdadeira para o caso concreto, de maneira que não restava à Corte, senão desviar das regras até então válidas, para construir outra solução (equidade).

Uma hipótese de alteração do sentimento moral da sociedade ${ }^{15}$ sobre um tema jurídico pode ser percebida no voto do Ministro Ayres Britto na ADI n. ${ }^{\circ} 4277$ do STF ${ }^{16}$, que versou sobre o reconhecimento jurídico da união homoafetiva.

O Ministro afirma, inicialmente, que a palavra "sexo" aparece na Constituição "para emprestar a ela o nítido significado de conformação anátomo-fisiológica descoincidente entre o homem e a mulher." No entanto, sua argumentação evolui para evidenciar que o referido termo também tem outros sentidos que se referem aos "domínios do instinto e não raro com a prevalência dele no ponto de partida das relações afetivas."

A par destas premissas o Ministro passa a desenvolver o segundo sentido do termo, para afirmar que: "se as pessoas de preferência heterossexual só podem se realizar ou ser felizes heterossexualmente, as de preferência homossexual seguem na mesma toada: só podem se realizar ou ser felizes homossexualmente."

Esta transposição de sentidos linguísticos (decorrentes de alteração na percepção social de um signo) é afirmada pelo próprio Ministro, quando afirma que: "o século XXI já se marca pela preponderância da afetividade sobre a biologicidade. Do afeto sobre o biológico, este último como realidade tão somente mecânica ou automática, porque independente da vontade daquele que é posto no mundo como conseqüência da fecundação de um individualizado óvulo por um também individualizado espermatozóide."

Com estes argumentos, o Ayres Britto concluiu que para a formação de uma família pouco importa se ela é "formal ou informalmente constituída, ou se integrada por casais heterossexuais ou por pessoas assumidamente homoafetivas", já que a família é um "fato cultural e espiritual ao mesmo tempo (não necessariamente como fato biológico)."

\footnotetext{
${ }^{15}$ A expressão "sentimento moral da sociedade" é muito vaga e levanta sérias questões sobre quem estaria legitimado para dizer que a sociedade, como um todo, deve interpretar uma questão importante de um jeito ou de outro. Numa democracia seria de esperar que tais questões fossem decididas pelos mecanismos de representação e de participação popular. Este era o objetivo, exemplificativamente, da PEC 37. Todavia, também há uma profunda polêmica sobre quais assuntos podem ser submetidos a este tipo de controle social. Faz-se se o registro da polêmica, e, invoca-se o exemplo da união homoafetiva, para o fim de exemplificar mais uma das hipóteses da aplicação da equidade, sem polemizar sobre como deveria ser apreendido o "sentimento moral da sociedade", se por meio de instâncias majoritárias (ex: Legislativo) ou contramajoritárias (Judiciário).
} 
Muito embora o Ministro Ayres Britto não faça menção explícita à equidade, esforçando-se para evidenciar que sua motivação já se encontrava na Constituição desde sua redação, não se pode ignorar sua interpretação no sentido de que as uniões, protegidas pelo direito, sofreram uma gradual alteração. E isto fica bem evidente quando o Ministro menciona a alteração no conceito de "sexo" (e de união entre pessoas do mesmo sexo), que passa do critério biológico, para o critério afetivo. E é por meio desta alteração (na forma como a sociedade interpreta seus conceitos, ou ao menos, a mais alta Corte do Poder Judiciário) que foi possível concluir que não só a união entre homem e mulher (no sentido biológico) é protegida, mas, também aquela união (estável) de duas pessoas do mesmo "sexo" biológico.

Há ainda o caso do reconhecimento da licitude do aborto no caso do feto anencéfalo (ADPF n. ${ }^{0} 5{ }^{17}$ ), na qual o Supremo Tribunal Federal invoca, literalmente, a aplicação da equidade, consoante se extrai do voto do Ministro Luiz Fux:

"Consectariamente, o atual art. 128 do Código Penal, que prevê as causas de justificação no crime de aborto, deve sofrer uma releitura, à luz das novas necessidades científicas e sociais. Os hodiernos métodos de diagnóstico da anencefalia durante a gravidez inexistiam à época da edição da parte especial do Código Penal brasileiro. Basta ver que o primeiro estudo sobre o possível uso do ultrassom como ferramenta de medicina diagnóstica surgiu em 1940, por pesquisadores da Universidade de Colônia, na Alemanha (GOHR, H.; WEDEKIND, T. Der Ultraschall in der Medizin. In: Journal of Molecular Medicine, Vol. 19, No. 2. (1 January 1940), pp. 25-29). Em 31 de dezembro do mesmo ano, era publicado o Estatuto Repressivo do nosso país. A necessidade de interpretação evolutiva é patente, na medida em que o Anteprojeto do novo Código Penal inclui mais uma hipótese de aborto permitido, no art. 127, III, quando "há fundada probabilidade, atestada por dois outros médicos, de o nascituro apresentar graves e irreversíveis anomalias que o tornem inviável". A lacuna normativa atual não deve conduzir à incriminação da conduta, sendo o caso de recurso à equidade integrativa, de que tratou Aristóteles na sua "Ética a Nicômaco", para permitir o preenchimento da omissão legislativa com aquilo que teria dito o legislador se tivesse conhecido do caso em questão. (depois vai chamar de princípio da proporcionalidade)"

Noutro precedente $\left(\mathrm{HC} \mathrm{n.}{ }^{0} 113857 / \mathrm{AM}^{18}\right)$, o Supremo Tribunal Federal invoca a equidade para afastar $\left(\right.$ derrotar $^{19}$ ) a regra do art. 88, II do CPM (que proibia a suspensão condicional da pena no caso de crime de deserção, que é considerando menos grave) por violação à proporcionalidade, preceito segundo o qual não se deve fixar "penas exageradas para infrações de menor potencial ofensivo". Daí a afirmação do Min. Dias Toffoli de que "a norma em questão avilta mais diretamente a equidade, pela qual se espera harmonia na aplicação dos

\footnotetext{
${ }^{16}$ STF, ADI 4277/DF, Rel. Min. Ayres Britto, Tribunal Pleno, j. 05.05.2011, DJe-198, p. 14.10.2011, Ement. Vol. 02607-03, p. 341, RTJ vol. 00219, p. 00212.

${ }^{17}$ STF, ADPF n.o 54/DF, Rel. Min. Marco Aurélio, j. 12.04.2012, Tribunal Pleno, j. 12.04.2012, DJe-080, p. 30.04.2013.

${ }^{18}$ STF, HC 113857/AM, Rel. Min. Dias Toffoli, Tribunal Pleno, j. 05.12.2013, DJe 213, p. 30.10.2014.

${ }^{19}$ Como afirmou o Ministro Marco Aurélio, no Recurso Extraordinário n.o 567.985/MT: "Posta a questão em jargão técnico, o Poder Judiciário derrotou uma regra. $\mathrm{O}$ dispositivo legal fornecia relato preciso e acabado da hipótese efetiva de atuação, o qual ficou suplantado pelo aplicador em favor de concepção mais ampla de justiça. Além disso, não se teceu sequer consideração quanto à validade da regra, que permanece hígida em abstrato. Desse quadro, é possível asseverar que se tem a constitucionalidade em abstrato do preceito legal, consoante assentado pelo Supremo, mas a inconstitucionalidade em concreto na aplicação da norma, consideradas as circunstâncias temporais e os parâmetros fáticos revelados." (p.9)
} 
princípios constitucionais e das normas infraconstitucionais."

Consoante se extrai do precedente, nem sempre é possível qualificar a aplicação da equidade de maneira exata, em uma das hipóteses anteriormente indicadas. De toda forma, é incontroverso que a equidade é um recurso contra a lei, quando a sua aplicação (ou da regra de justiça, ou do precedente), mostraram-se iníquas.

A dinâmica da equidade é interessante e peculiar. Ao encontrar-se na fronteira do direito, sendo o último recurso à preservação da razoabilidade (e/ou da proporcionalidade) da ordem jurídica, ela pode oferecer respostas surpreendentes, seja pelo grau de racionalidade e de justiça de seus comandos, seja pelo caráter arbitrário e decisionista que pode assumir.

\section{PONDERAÇÕES SOBRE O VALOR RACIONAL DE UMA DECISÃO EQUITATIVA}

Diz-se que uma decisão equitativa é tão melhor quanto maior a profundidade com que se analisa o caso concreto, e quão abrangente é a interpretação dos institutos jurídicos envolvidos na discussão. Essa medida é considerada tanto no plano vertical (investigação sobre os fundamentos de justiça, ou, da razão de ser de um instituto jurídico), quanto no plano horizontal (capacidade de estabelecer relações e encontrar soluções interessantes para outros casos similares; trata-se da força gravitacional do novo precedente, que se espraia para a solução de outros casos) ${ }^{20}$. E quanto mais ela se sustenta frente às outras opções de solução do caso concreto, produzindo um efeito propagador para outros casos similares, mais a solução encontrada tenderá a complementar o ordenamento jurídico (DWORKIN, 2002, p. 191).

Mas, o contrário também vale. Uma decisão que se desvia da regra positivada e tem pouca abrangência, ou parece ignorar valores fundamentais de uma ordem jurídica, têm poucas chances de persistir aos testes de justificação e racionalização que se exigem desse tipo de decisão. Não se ignora que algumas decisões "equitativas" perduram no tempo, o que poderia dar a impressão de que são efetivamente razoáveis. No entanto, não é somente o tempo de vigência do precedente que torna uma decisão equitativa melhor, mas, o teste argumentativo ao qual ele é submetido.

\footnotetext{
${ }^{20} \mathrm{Em}$ que pese o art. 469 do CPC de 1973 afirmar que "não fazem coisa julgada" "os motivos, ainda que importantes para determinar o alcance da parte dispositiva da sentença”, o fato é que não se pode ignorar a relevância das teses jurídicas apresentadas nas decisões judiciais, especialmente, aquelas que aplicam a equidade, sob pena de se admitir o casuísmo, que é contrário a pretensão de segurança da ordem jurídica. Esta disposição também é encontrada no novo $\mathrm{CPC}$, em seu art. 504. Para que se mantenha a lógica de preservação da força dos precedentes (e também, a possibilidade de sua revisão), é necessário que estes dispositivos sejam interpretados no sentido de que os fatos invocados como motivos não fazem coisa julgada. No entanto, as razões jurídicas, devem ser acobertadas sob o manto da coisa julgada. Pois é partir destes argumentos jurídicos que se mede a força gravitacional, ou seja, a força e a abrangência de um instituto ou de uma interpretação, seja para aplicá-los a outros casos similares, seja para afastá-los e superá-los (overruling).
} 


\section{Exemplos e contraexemplos sobre a justificação de decisões que se afastam de regras e precedentes pré-existentes}

Um exemplo ilustrará as dificuldades que a necessidade de justificação e racionalização das decisões equitativas representa para o intérprete.

No Recurso Extraordinário n. ${ }^{\circ} 500.171 / \mathrm{GO}^{21}$ a Universidade Federal de Goiás pretendia validar a cobrança de "contribuições" de seus estudantes ${ }^{22}$. O Supremo Tribunal Federal entendeu que tal exigência é manifestamente inconstitucional, por violar o art. 205 da Constituição, o qual estabelece a gratuidade do acesso ao ensino público. Até aqui o esforço hermenêutico não era significativo.

Mas, a Universidade opôs embargos de declaração ${ }^{23}$ argumentando que a Corte deveria modular os efeitos da decisão. Noutros termos, pretendeu a Universidade restringir os efeitos da decisão que lhe era desfavorável, de maneira que os estudantes, que ainda não tivessem ajuizado ação para reaver os valores indevidamente cobrados, não teriam direito à restituição. ${ }^{24} \mathrm{O}$ argumento central da universidade era o seguinte: “(...) o problema que pode advir com o presente julgado é o entendimento no sentido de que as contribuições anteriormente cobradas devam ser restituídas, o que poderá gerar incontáveis demandas, com potencial para desestabilizar financeiramente as aludidas instituições."

Perceba-se que o argumento da Universidade não é de que ela teria direito de cobrar as "contribuições" dos estudantes, mas, de que não poderia devolver o que cobrou indevidamente, porque suas finanças seriam desestabilizadas. Ou seja, o argumento estritamente econômico deveria suplantar o direito dos estudantes, que ainda não teriam ajuizado a ação.

E, esta tese prevaleceu sob o fundamento de que a Universidade de Goiás, e as demais instituições públicas que praticavam a cobrança, poderiam sofrer graves reveses financeiros, desequilibrando suas contas. Não foi objeto de ponderação pelos Ministros, por exemplo, a possibilidade de as Universidades buscarem recursos orçamentários junto à União, mediante a atuação republicana de seu corpo docente e discente, de maneira a suplantar as cobranças ilícitas feitas anteriormente. Também não se cogitou sobre a possibilidade de a

\footnotetext{
${ }^{21}$ STF, RE 500171/GO, Rel. Min. Ricardo Lewandowski, Tribunal Pleno, j. 13.08.2008, DJe-202, p. 24.10.2008, Ement. Vol. 02338-05, p. 1014, LEXSTF v. 30, n. ${ }^{\circ} 360$, 2008, p. 174-198.

${ }^{22}$ Tais "contribuições" ou "taxas" eram exigidas dos estudantes que tinham melhores condições financeiras e incidiam no momento de realização de matrículas, requerimentos administrativos, etc.

${ }^{23}$ Os embargos de declaração caracterizam-se como meio recursal dirigido ao julgador que proferiu a decisão, objetivando aperfeiçoá-la, em razão de omissão, obscuridade ou contradição. O cabimento deste recurso no caso concreto é, no mínimo, discutível. Mesmo assim, o STF analisou. Nesse sentido: RE 500171 ED/GO, Rel. Min. Ricardo Lewandowski, j. 16.03.2011,

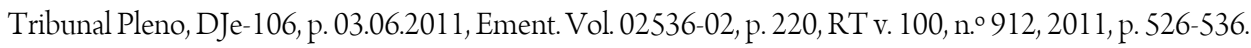

${ }^{24}$ Sem a modulação de efeitos, a decisão seguiria a regra geral de que havendo um ilícito deve-se repará-lo. O ilícito constitui-se na cobrança de taxas indevidas (ainda que fundadas em bons propósitos), porque inconstitucionais. Logo, todos os estudantes que pagaram quantias indevidas ao Estado (aqui representado pela UFGO) teriam direito à restituição, independentemente de terem ajuizado a ação um dia antes, ou, um dia depois da decisão do STF. Mas, este não foi o desfecho do caso. 
Universidade buscar outras fontes de financiamento para suas atividades, a partir das pesquisas e estudos sustentados pela arrecadação tributária.

A solução para a questão, ainda que bem-intencionada, foi tomada de modo prático, ou seja, ratificando a cobrança indevida. ${ }^{25}$ Mas, deixando de lado as boas intenções, se sustentaria o argumento subjacente de que o Estado pode ser desobrigado de reparar um dano ilicitamente causado, quando invocar suas dificuldades financeiras? Este raciocínio pode ser considerado consistente e imparcial, caso invertam-se os seus termos? ${ }^{26} \mathrm{Em}$ última análise, teria este precedente a força de sustentar a resolução de outros casos que não envolvam somente o Estado ou em que ambos os litigantes são pessoas de direito público com orçamentos significativamente diferentes (ex: União x Município), ou ainda quando o Estado fosse o credor da dívida indevidamente exigida? A resposta parece ser negativa.

Perceba-se que a questão central do problema sobre o poder interpretativo das soluções equitativas não está no uso da "modulação de efeitos", mas, sim nas soluções que são extraídas a partir do seu emprego.

Outro exemplo auxiliará na ilustração do argumento.

Na ADI n. ${ }^{0} 3689^{27}$ do STF dois municípios (Ourilândia do Norte e Água Azul do Norte) disputavam a validade do desmembramento de seus territórios. Na verdade, o desmembramento fora feito com a concordância de ambos, seguindo o procedimento de uma Lei Estadual. Passados vários anos do desmembramento, um partido político ajuizou em favor do município de Água Azul do Norte a referida ADI argumentando que o desmembramento era inconstitucional porque, a partir da Emenda Constitucional n. ${ }^{\circ}$ 15/96, somente poderia ocorrer se observados os requisitos de lei federal. ${ }^{28}$

A inconstitucionalidade do desmembramento é evidente e, a exemplo do caso anteriormente apresentado (RE 500.171/GO), não há um esforço hermenêutico significativo para chegar a esta conclusão.

\footnotetext{
${ }^{25}$ A questão tem um apelo social, porque os estudantes pobres não estavam obrigados a pagar as "contribuições". Somente os com melhor condição financeira as pagavam. Mas, este argumento social é perigoso, porque dele pode-se extrair ser possível ratificar uma cobrança ilícita, quando ela atinja as finanças dos que tenham capacidade contributiva. A seguir esta premissa, a própria ideia de limitação ao poder de tributar (própria do Estado de Direito), deixaria de fazer sentido.

${ }^{26}$ Apenas para exemplificar a dificuldade da tese vencedora no STF, tome-se como hipótese a situação de uma empresa que obteve em seu favor várias decisões judiciais favoráveis, autorizando-a a não pagar um tributo. Imagine-se que isso ocorreu durante 15 anos. Porém, na última instância (STF), as decisões que lhes eram favoráveis são cassadas e ela passa a ser obrigada a pagar todos os tributos (dos últimos 15 anos). Certamente a empresa invocará razões de ordem financeira para justificar que somente terá que pagar os tributos de agora em diante, já que o débito dos últimos 15 anos é gigantesco, o que poderá ensejar a insolvência da empresa, a demissão de funcionários etc. Este argumento sensibilizaria a Corte Suprema? Esta discussão ficou bem evidente no julgamento do Recurso Extraordinário n. ${ }^{3}$ 370.682/SC. O Min. Lewandovski convenceu-se desta tese porque: "(...) sobreveio uma alteração substancial no entendimento do STF sobre a matéria, possivelmente em face de sua nova composição, entendo ser conveniente evitar que um câmbio abrupto de rumos acarrete prejuízos aos jurisdicionados que pautaram suas ações pelo entendimento até agora dominante." (p. 12 do acórdão). Mas, esta tese foi vencida.

${ }^{27}$ STF, ADI n. ${ }^{3689}$ /PA, Rel. Min. Eros Grau, Tribunal Pleno, j. 10.05.2007, DJe-047, p. 29.06.2007, DJ 29.06.2007, p. 22, Ement. Vol. 02282-04, p. 635.

${ }^{28}$ Até o momento não existe uma lei federal que regulamente o desmembramento de municípios. As propostas aprovadas pelo legislativo federal foram vetadas pelo Poder Executivo.
} 
A consequência mais imediata ${ }^{29}$ é que o Município derrotado (Ourilândia do Norte), que havia incorporado parte do território (e da população) do Município vencedor, teria, por exemplo, que restituir recursos que lhes foram repassados em razão do número de pessoas que habitavam no território incorporado. Diante disso, o próprio STF passou a ponderar sobre a modulação de efeitos, no sentido de preservar as relações jurídicas havidas no território dos municípios.

O relator Min. Eros Grau entendeu que no território de ambos os Municípios se realizaram eleições, que contou com votos dos moradores do território desmembrado/incorporado. Também ali se instituiu e arrecadou tributos, prestaram-se serviços públicos, exerceu-se o poder polícia, foram celebrados casamentos, registros de nascimentos e óbitos. Os Municípios receberam recursos federais e estaduais que correspondem ao referido território, que "está contido, de fato, no Município de Ourilândia do Norte, a partir de uma decisão política consolidada. Esta realidade não pode ser ignorada. Em boa-fé, os cidadãos domiciliados na faixa de terra próxima da sede do Município de Ourilândia do Norte supõem seja juridicamente regular e legítima a integração dessa gleba ao Município."

No decorrer do voto, o Ministro Eros Grau enfatiza a excepcionalidade da situação e invoca outros princípios para resolver a questão, além de evidenciar a existência de omissão inconstitucional atribuível ao poder legislativo federal, que não editou a lei complementar necessária à regulamentação da situação.

A premissa de seus argumentos evidencia que, para além da preservação da situação jurídica dos Municípios (pessoas jurídicas de direito público), há uma relevante tese subjacente, qual seja a preservação do direito adquirido, dos atos jurídicos perfeitos e das expectativas legítimas geradas às pessoas residentes em ambos os Municípios, cuja "boa-fé [foi] nutrida inclusive pelo fato de que a Lei estadual n. 6.066 é de 1.997. Os interessados na declaração de inconstitucionalidade dela, a lei, poderiam ter pleiteado a extirpação do ato já há nove anos. Não o fizeram. Fazem-no agora, posteriormente à confirmação da localização de uma reserva de níquel laterítico no local."

Desse modo, para que o interesse meramente financeiro de um dos Municípios (pessoa jurídica de direito público) não prevalecesse sobre os interesses dos particulares de ambos os entes federados, é que o Ministro entendeu que "essa integração consubstancia uma situação consolidada. O nomos do seu território foi nele instalado de modo a abranger esse território. O Município legislou, de modo que uma parcela do ordenamento jurídico brasileiro é hoje composta pela legislação local emanada deste ente federativo que alcança a região ora reclamada pelo Município de Água Azul do Norte.”

Ou seja, neste caso há um ingrediente sobremodo relevante que justifica a manutenção do desmembramento territorial, apesar de inconstitucional. É que pessoas (físicas ou jurídicas), de boa-fé, poderiam

\footnotetext{
${ }^{29}$ A declaração de inconstitucionalidade na ADI, em regra, tem como consequência a anulação das relações jurídicas havidas sob a vol.09, nº. 04, Rio de Janeiro, 2016. pp. 1935-1954 1948
} 
ter afetadas suas relações jurídicas, caso fosse aplicada a sistemática de julgamento de inconstitucionalidade com efeitos retroativos.

Ora, a decisão não tomou como primeiro fato relevante a proteção das finanças do Município de Água Azul do Norte (que venceu a demanda), mas, a preservação das relações jurídicas transcorridas nos últimos anos (em ambos os municípios), as quais seriam afetadas significativamente se não houvesse a modulação de efeitos. Daí decorre que a modulação se operou não só com o intuito de preservar o interesse da pessoa jurídica de direito público, mas, especialmente, de garantir a paz, a tranquilidade e o bem-estar da segurança jurídica para os habitantes dos Municípios (as pessoas privadas).

Desse elemento essencial à compreensão da discussão extrai-se uma premissa diferente daquela realçada no julgamento do RE n.o $500.171 \mathrm{ED} / \mathrm{GO}$, no qual se tomou uma posição nitidamente favorável à preservação das finanças da Universidade, sem que se evidenciasse que a Universidade figuraria como terceiro de boa-fé, que não deu causa direta ao ato (apesar de bem-intencionado) declarado inconstitucional.

Ainda que se tente tornar defensável a posição da Universidade, não se pode ignorar que as circunstâncias fático-argumentativas que envolvem os casos são diferentes.

No caso da Universidade, os estudantes que pagaram a "contribuição" indevida (e que não tinham ajuizado a ação até o julgamento do recurso) tiveram seu direito de acessar o Judiciário denegado (art. 5º XXXV, da $\mathrm{CF}$ ) quando eles eram os terceiros de boa-fé que não deram causa ao ato ilegal. No caso dos Municípios, os terceiros de boa-fé (os munícipes) foram resguardados pela modulação de efeitos.

A diferença das premissas evidencia uma contradição importante entre os referidos precedentes. Ambos se desviam da regra de justiça, ou seja, da sistemática tradicional e esperada do controle de constitucionalidade. Nesse sentido, ambas as decisões se abrem para a possibilidade de aplicação da equidade. Todavia, uma faz um uso mais adequado da equidade, ao passo que a outra apresenta critérios, no mínimo, questionáveis (para não dizer parciais, na medida em que favorece a parte que deu causa à inconstitucionalidade).

Como se extrai dos exemplos e contraexemplos, apesar da equidade prestar-se à complementação do ordenamento jurídico, tornando-o mais justo e adequado às circunstâncias sociais, políticas e econômicas atuais, o fato é que ela também pode ser arbitrária e agressiva ao um conjunto de valores e de direitos importantes para a sustentação da Constituição.

\section{Observações sobre os valores (imparciais) que embasam decisões equitativas}

Aqui surge uma questão fundamental para a vertente casualista: quais valores inspiram a construção das soluções equitativas?

vigência da lei declarada inconstitucional (efeito ex tunc). 
Chaïm Perelman, um dos que reintroduziu modernamente o pensamento de Aristóteles, especialmente quanto ao uso da equidade, da retórica e da argumentação no direito, sugere dois níveis (interligados) de solução para o problema.

Num primeiro nível verifica-se o caráter formal, geral e abstrato para a construção da solução equitativa. O autor adapta o imperativo categórico kantiano para a análise de casos concretos. Assim, a partir do contexto de argumentação de cada uma das partes envolvidas na discussão procura-se construir enunciados normativos, que possam ser universalizados, de maneira que uma máxima parcial (relativa a uma das partes no conflito) possa tornar-se compreensível à parte adversa. Ou seja, não um conteúdo predeterminado para o valor que inspirará a solução do caso concreto. Há apenas o valor formal da tese, que deve ser formulada com pretensão de universalidade.

A partir dos exemplos anteriormente analisados, pode-se explicar esta forma de construir a argumentação. Os estudantes que pagaram a "contribuição" indevida à Universidade (RE n.o 500.171/GO) argumentavam que terceiros de boa-fé devem ser reparados dos danos que sofrerem. Este argumento pode ser formulado de maneira imperativa, com pretensão de universalidade, nos seguintes termos: todo aquele que causar um dano a um terceiro de boa-fé deve repará-lo; ou, aja de tal maneira que não causes dano a ninguém e, se causares, indenize-o.

Já o argumento da Universidade pode ser formulado nos seguintes termos: sempre que o Poder Público causar um dano, não terá que repará-lo, se demonstrar que ele decorre de bons motivos (ex: favorecer os menos favorecidos) e se seus recursos financeiros forem afetados substancialmente.

Num segundo nível procura-se convencer um auditório (universal), por meio da retórica e dos instrumentos de argumentação, a fim de demonstrar que a máxima pretensamente universal do argumento é a melhor solução para o caso concreto (mais imparcial). Aqui a tarefa é de demonstrar que uma máxima é mais imparcial que outra. A dialeticidade argumentativa se estabelece com o objetivo de mostrar a imparcialidade do próprio argumento e denunciar a parcialidade da tese oposta.

Valendo-se das máximas anteriormente apresentadas, os estudantes poderiam argumentar que a tese da Universidade é menos imparcial do que a por eles apresentada, isto porque, a hipótese de não se reparar um dano somente é justificável sob a perspectiva de quem não quer arcar com a indenização.

Ou seja, ao passo que o argumento dos estudantes seria válido sob o ponto de vista da Universidade se ela fosse credora, o mesmo não ocorreria se os estudantes fossem os devedores de alguma obrigação regularmente imposta pela Universidade.

Para que a máxima da Universidade fosse tão imparcial quanto a dos estudantes, teria que demonstrar hipóteses em que os estudantes (sem boa-fé) estariam desobrigados de adimplir um dever legitimamente imposto, porque a obrigação iria afetar substancialmente sua condição financeira. 
No caso analisado, o STF não foi capaz de demonstrar qual seria o argumento mais imparcial da Universidade, de maneira que, em princípio, deveria ter prevalecido o argumento dos estudantes ${ }^{30}$, por ser o mais imparcial, ou seja, aquele que ambas as partes reconheceriam como válido se estivessem em posições opostas.

Este processo argumentativo (de convencimento) não tem um critério último de decisão sobre qual tese é a mais justa, indicando apenas que a justificação do intérprete não pode manifestar um posicionamento pessoal, tampouco constituir-se numa defesa de interesses particulares, que seria inaceitável para aqueles que serão afetados pela decisão a ser tomada (PERELMAN, 1996, p. 205).

Perelman não apresenta um conjunto de valores a partir do qual se constrói uma solução para os casos difíceis. Ao contrário, ele critica tal pretensão (dos abstracionistas) acusando-a de irreal e insuficiente para resolver problemas situados num tempo histórico.

Nesse sentido, somente a discussão do caso concreto e sua análise retrospectiva revelará a imparcialidade da decisão equitativa. Isso significa que numa reavaliação argumentativa é possível revisar o entendimento então firmado, se o intérprete for capaz de encontrar argumentos mais imparciais que os anteriormente empregados.

Alguns autores da vertente casualista tentaram tornar menos arbitrária a construção dos argumentos equitativos, procurando desenhá-la não por meio da retórica, mas, por intermédio de um "cálculo racional" de ponderações e considerações de argumentos (a exemplo de R. Alexy com a esquematização matemática da interpretação).

A despeito destas tentativas de racionalização sobre a equidade, paira a acusação de que ela, em alguma medida será arbitrária, subjetiva e antidemocrática, na medida e que é empregada por agentes públicos que substituem o legislador eleito.

É que permanece um tanto misteriosa a forma de controlar as instituições que aplicam a equidade. Em casos mais extremos, a equidade pode destruir as bases de um ordenamento jurídico, produzindo um caráter mais Político, que jurídico para a solução de conflitos. Nesse contexto, teme-se a juristocracia, ou, a revolução institucional feita sob bases e por autoridades sem poder para, originariamente, criar uma nova ordem jurídica. Receia-se a desfragmentação do sistema jurídico, o que poderia levar a uma incerteza insuportável sobre seus valores mais elementares, destruindo-se qualquer possibilidade de consenso valorativo sobre o direito. ${ }^{31}$

\footnotetext{
${ }^{30}$ Neste caso, bastaria aplicar a regra geral do dever de indenizar, dispensando-se a aplicação da equidade, até porque o STF não foi capaz de demonstrar que o caso da Universidade era peculiar, decorreu de uma mudança abrupta no contexto econômico ou de uma evolução no sentimento moral da sociedade. Mas, o caso da Universidade é diferente do retratado na ADI n. ${ }^{\circ}$ 3689/PA, no qual ficou clara que a aplicação da equidade decorreu de uma situação peculiar (uma dupla inconstitucionalidade, por ação e por omissão), na qual se afastou o controle tradicional de constitucionalidade para preservar a condição jurídica dos terceiros de boa-fé (os habitantes de ambos os Municípios). Além disso, a tese de que não se deve afetar o direito adquirido do terceiro de boa-fé mostrou-se mais imparcial do que aquela que privilegiaria o Município vencedor da demanda (que seria favorecido pela declaração de inconstitucional com efeitos retroativos), posto, que o seu objetivo mostrou-se estritamente de caráter econômico.

${ }^{31}$ Sem entrar no mérito da discussão, mas, apenas para ilustrar as dificuldades anunciadas, cita-se o exemplo da decisão do STF sobre o reconhecimento da união estável homoafetiva e a interpretação feita pelo STJ sobre este precedente. O STF não ingressou vol.09, n. 04, Rio de Janeiro, 2016.pp. 1935-1954 1951
} 
Daí a advertência de Canotilho de que "nem sempre se consegue manter um discurso argumentativo", porque se entrecruzam discursos sobre o processo de argumentação, discursos axiológicos estruturados em torno de conceitos morais, discursos hermenêuticos de mundos parciais (da economia, da ética, da biologia) (CANOTILHO, 2003, p. 1351).

Em que pese os riscos da vertente casualista, os quais depõem contra o emprego da equidade, não há uma solução definitiva para o problema posto, já que ela não se propõe a investigar níveis mais abstratos sobre o conteúdo as ideias que fundam uma ordem constitucional, ou sobre os institutos e valores jurídicos empregados na discussão de casos difíceis. Eis uma limitação inerente à vertente, que, em razão de seus pressupostos, não pode elevar-se para além do contexto da própria argumentação. De toda forma, o esforço argumentativo é algo melhor que a simples reprodução de uma regra ou precedente pré-existente injusto.

\section{Conclusão}

Apesar da desconfiança e da ainda tímida aceitação do uso da equidade, este recurso interpretativo é valoroso, na medida em que pretende evitar a tomada de decisões arbitrárias.

Para realçar este propósito apresentou-se a distinção entre a vertente casualista e a abstracionista, destacando-se que ambas pressupõem a insuficiência do ordenamento jurídico, que a equidade, para sua incidência, independente de previsão do ordenamento jurídico, modulando, adaptando e até diminuindo a força dos institutos clássicos do direito.

Ao enfocar a vertente casualista, mostrou-se que a equidade é necessária para evitar injustiças, mas que a segurança jurídica somente pode a ela ceder espaço em três hipóteses: a) em situações peculiares não previstas pelo legislador (ex: concurso público para funções especiais); b) quando há uma alteração significativa no contexto de constituição e aplicação de uma regra (ex: abrupta desvalorização da moeda); c) quando há uma alteração no sentimento moral da sociedade (ex: união homoafetiva).

Ponderou-se, ao final, que uma decisão equitativa é tão mais justa quanto mais os argumentos por ela empregados são capazes de se aplicarem a outros casos similares, mas especialmente, se conseguir reposicionar a compreensão de institutos jurídicos, de maneira a construir uma teia argumentativa que complemente o ordenamento jurídico, circunstância que nem sempre é alcançada, conforme se verificou nos exemplos e contraexemplos analisados a partir dos precedentes do Supremo Tribunal Federal.

na discussão sobre a possibilidade de casamento entre pessoas do mesmo sexo, evitando uma polêmica ainda maior com grupos sociais que invocam o conceito "tradicional" de família. O STJ, porém, sustentando-se no referido precedente, ingressou na polêmica e aplicou o referido entendimento também para o casamento. A questão a ser levantada diz respeito à força gravitacional e aos efeitos transcendentes que um precedente (fundado numa decisão equitativa) pode ter em relação a outros valores da ordem jurídica. Quais valores e premissas podem ser transplantados, legitimamente, para outros casos? Como manter a coerência do direito, ante tal possibilidade de transposição argumentativa? Estas são questões difíceis, que desafiam a vertente casualista. vol.09, no. 04, Rio de Janeiro, 2016.pp. 1935-1954 
De toda forma, a pretensão de complementação do ordenamento jurídico pode se dar em dois níveis.

Num primeiro, adapta-se o imperativo categórico, procurando universalizar as máximas que pretendem equacionar a questão. Num segundo, procura-se demonstrar que as opções concorrentes são menos justificáveis e imparciais. Como afirma Perelman:

"É essa intenção de universalidade, cuja realização efetiva jamais é assegurada, que caracteriza a argumentação racional. Esta não pode, como uma técnica demonstrativa, definir-se por uma conformidade com regras prescritas de antemão. Os argumentos não são, como um raciocínio demonstrativo, corretos ou incorretos; são fortes ou fracos, relevantes ou irrelevantes." (PERELMAN, 1996, p. 203).

Há várias formas de empreender argumentos razoáveis para formar convencimento, a exemplo da retórica, mas as limitações argumentativas devem ser reconhecidas. Apesar das limitações da vertente casualista, o esforço por ela exigido é indispensável, na medida em que pode possibilitar a melhor solução para casos difíceis que não seriam resolvidos pelas regras e precedentes já conhecidos.

\title{
EQUITY BETWEEN JUSTICE AND POLITICS: CASUIST PERSPECTIVE
}

\begin{abstract}
The article is about equity, which is understood as a resource to the interpreter against the law and precedent. From research of doctrinal texts, judicial decisions and the Brazilian law, equity is presented in two perspectives, the casuist and abstractionist. It analyzes the casuist side, indicating and exemplifying the cases that the country's courts apply it. Some Supreme Court precedents demonstrate that equity can be more wicked than traditional decisions. However, arguments conducted impartially, publicly justifiable, can improve the quality of the trial by equity, making it more reasonable to solve hard cases.
\end{abstract}

Keywords: equity, justice, casuist perspective, justification.

\section{REFERÊNCIAS BIBLIOGRÁFICAS}

ARISTÓTELES. Ética a Nicômacos. 4a ed., trad. Mário da Gama Kury, Brasília: UNB, 2001.

CANOTILHO, J.J. Gomes. Direito Constitucional e Teoria da Constituição, 7a Ed, 4a reimpressão, Coimbra: Almedina, 2003.

DWORKIN, Ronald. Levando os direitos a sério. trad. Nelson Boeira. São Paulo: Martins Fontes, 2002.

HABERMAS, Jürgen. Direito e democracia: entre facticidade e validade. v. 1 e 2 trad. Flávio Beno Siebeneichler. Rio de Janeiro: Tempo Brasileiro, 1997.

KANT, Immanuel, A metafísica dos costumes, Trad. Edson Bini, Bauru: EDIPRO, 2003. 
KELSEN, Hans. Teoria Pura do Direito, trad. João Baptista Machado, 6ª ed., São Paulo: Martins Fontes, 2003.

OLIVEIRA, Francisco Cardozo. Hermenêutica e tutela da posse e da propriedade. Rio de Janeiro: Forense, 2006.

PERELMAN, Chaïm. Ética e direito. Trad. Maria Ermantina Galvão. São Paulo: Martins Fontes, 1996.

RAWLS, John. O liberalismo político. 2a ed. trad. Dinah de Abreu Azevedo. São Paulo: Editora Ática, 2000a.

Uma teoria da justiça $2^{a}$ ed. Trad. Almiro Pisetta; Lenita Maria Rímoli Esteves. São Paulo: Martins Fontes, 2002a.

Justiça como eqüidade: uma reformulação. Trad. Claudia Berliner. São Paulo: Martins Fontes, 2003.

SCHMITT, Carl. El Leviathan em la teoría del Estado de Thomas Hobbes, trad. Francisco Javier Conde, Granada: Editoral Comares, 2004.

VARGAS, Jorge de Oliveira. Julgamento por equidade. Curitiba: Juruá, 2015.

Trabalho enviado em 15 de março de 2016.

Aceito em 14 de julho de 2016. 